\title{
Key problems hindering the development of co- operation in the agricultural sector of Russia
}

\author{
Evgeniya Krinichnaya ${ }^{1 *}$ and Marina Kholodova $^{1}$ \\ ${ }^{1}$ Federal Rostov Agricultural Research Centre, 1, Institutskaya str., 346735, p. Rassvet, Aksay district, \\ Rostov region, Russia.
}

\begin{abstract}
The article considers the key problems that hinder the development of the system of cooperation in the agricultural sector of Russia. It is argued that the spread of cooperative forms of interaction in rural areas is hampered by a number of specific factors, including demography, the concentration and consolidation of business in the face of large integrator companies, low efficiency in the use of land potential, material and financial resources, and state regulation. Special attention is paid to the state support for the development of agricultural cooperation and small-scale farming in rural areas. The geography of the location of the cooperative movement in the leading regions is presented. It is established that the development of cooperation occurs unevenly across the subjects of the Russian Federation, and its general state is still characterized as unstable. The comparative characteristics of the features of the development of agricultural cooperation in Russia and abroad are given. It is proved that in the modern Russian reality, agricultural cooperation is the new most effective form of cooperation in the agricultural sphere and a strategic tool of behavior that should not be ignored by small forms of management.
\end{abstract}

\section{Introduction}

In the context of the new economic reality cooperation is an objective necessity for the socioeconomic development of the agro-industrial complex of Russia. Cooperatives are one of the most promising forms of rural settlement infrastructure and can take a worthy place in the multi-layered structure of agricultural production. However, there are still unresolved problems that hinder the development of agricultural cooperation in our country.

\section{Research methodology}

The information base of scientific research was the publications of domestic scientists devoted to the subject under consideration, National reports on the implementation of the State Program for the Development of Agriculture and Regulation of Markets for Agricultural Products, Raw Materials and Food, data from the unified register of small and medium-sized

* Corresponding author: evgeniya270586@mail.ru 
businesses. In preparing the scientific article, were used analytical, monographic, statistical, economic methods and the method of graphic images.

\section{Research results}

Currently in many countries of the world, various cooperative practices have become widespread, which take forms from traditional to hybrid, bringing them closer to investor-oriented firms. In the Russian Federation, contrary to modern trends typical of Western countries, the revival of cooperation took place with a focus on traditional organizational forms, according to which cooperatives were focused on increasing the volume of transactions in order to achieve economies of scale in the absence of an incentive to create significant added value. Significant investments are needed to bring the cooperative product to a high level of readiness for consumption by the final buyer, but poorly specified property rights do not encourage domestic producers to invest in agricultural cooperatives [1].

The historical conditions in which agricultural cooperation developed in Russia create a more negative background for the perception and evaluation of its advantages. A large number of cooperatives were transformed from former collective farms, and many farmers still see the prospect of agricultural cooperation as a manifestation of the institutions of opportunism and coercion. However, the modern economy offers new forms of cooperation and behavioral strategies that should not be ignored by small businesses. State authorities should not only create and develop institutions that simplify the creation of cooperative structures and increase the efficiency of their functioning, but also conduct an information policy in this direction that contributes to changing the existing patterns of perception of such structures.

In many economically developed countries, information and consulting services have been established based on the material, technical, scientific and pedagogical base of agricultural and large regional multidisciplinary universities and their extensive links with various organizations, administrative and managerial structures. Within the framework of mutually beneficial cooperation, it also became possible to solve a number of problems in parallel, including in terms of establishing direct communication with production, passing practical training for students at small and medium-sized agribusiness enterprises.

This model, called «cooperative», is widely used in the United States of America, and similar organizations operate in many countries, including Spain, Germany and the Netherlands. Information and consulting services conduct consultations and demonstration activities on the rational organization of agricultural production, disseminate experience, new knowledge, etc. Their sources of funding are local, regional, federal budgets, sponsorship, grants and commercial activities [2].

The development and spread of cooperative forms are hindered by the peculiarities of the agricultural sector of the economy:

1. The global trend of shrinking and aging of the rural population and the population directly involved in the production of agricultural products significantly reduces the intensity of contacts of potential cooperators, especially when the cooperative tradition of small commodity producers has not developed or has been interrupted. The lower the density of the "population» of potential cooperators, the lower the number of possible initiators and leaders. Often, the functions of the initiators of cooperation are taken over by people who have the mentality of an entrepreneur. This can significantly reduce the level of trust of potential cooperators who are afraid of losing their independence in making managerial decisions.

2. Improvement of technologies, integration, concentration of production give agriculture the characteristics of industry. The enlargement of the size of farms leads to a gradual 
increase in the threshold of competitiveness for cooperating small agricultural producers. As a result of the development of technology, expensive and complex production and processing equipment has become widespread, which is not available both for individual farms and for start-up associations, while the introduction of advanced technologies is one of the most important areas of innovative development of the domestic agricultural sector.

3. Divergence between the circle of persons who own agricultural land and the circle of persons directly engaged in agricultural activities. Thus, an increasing part of the rural population is cut off from the main resource necessary for agricultural production, and unused land is exposed to adverse impacts (erosion, waterlogging, overgrowth with shrubs and forests, etc.) and goes out of circulation [3,4,5].

The weak development of agricultural cooperation, according to domestic economists, is associated both with problems of a macroeconomic nature and with intra-cooperative problems. The first group includes: unavailability of credit resources for many farmers, unsettled land relations, difficulties with the acquisition of resources and agricultural machinery and the sale of manufactured products. The formation of cooperatives is also influenced by the level of initial investment of shareholders, the real benefits and development strategy of the organization, the different potential and mutual trust of the members of the cooperative, state policy and cooperative legislation.

In addition to the above problems, it is necessary to highlight the following circumstances that prevent the creation of agricultural cooperation:

- lack of experience of potential cooperative members involved in this activity;

- difficulties in the selection of a professional and well-trained managers;

- high degree of monopolization of many market structures;

- loss of cultural traditions of conducting collective activities based on the principles of trust, solidarity and democracy [6].

Currently, not all agricultural cooperatives comply with the form stated in the charter, but carry out their activities in accordance with the selected main directions and developed plans and business strategies. Their functionality largely depends on the structure of the cooperative's membership base and market conditions. For example, processing cooperatives may be engaged in the cultivation of fruit crops, trade in tobacco products and carry out other types of economic activities that are not typical for enterprises engaged in the processing of agricultural products and raw materials. Supply and marketing cooperatives can produce and process products.

Sobolev A.V. and Pakhomov V. M. note that the legally established division of cooperatives does not contribute to their development, but on the contrary is an obstacle, since a lot of restrictions are created and compliance with various formal procedures is required. Currently, many consumer cooperatives do not have the opportunity to re-register and move from one legal form to another, as a result, there is a need to liquidate cooperatives and create new organizations. The self-liquidation of some cooperatives and the creation of others is a way to find more liberal taxes, preferential regulatory regimes and state support. As a result, «pseudo-cooperatives» are created, which can apply for state grants, financial assistance and other support at the local level [7].

A significant obstacle to the development of agricultural cooperation in our country is the predominance of the trend of excessive commercialization of the agricultural industry. For farmers, personal (family or individual) interests often dominate over group interests, and the desire to benefit at the expense of the interests of other participants leads to serious distortions and contradictions in the formation of a cooperative sector. The subjects in the conditions of the cooperative sector should be legally equal, but in practice, the interests of the owners of the controlling interest are often mainly taken into account, and the interests of small owners and employees are practically ignored [8]. 
The key factor determining the level of development of agricultural cooperation is state support, especially for small businesses. State support creates conditions for increasing the volume of agricultural production, meeting the needs of the population in food, increasing employment in rural areas, increasing the income of the population and developing rural areas.

Tax incentives and indirect measures to promote co-operation are also important. The positive experience of foreign countries, which can be used in domestic practice in the construction of a cooperative system, is of interest. Thus, in the countries of the European Union (EU), land-secured lending is widely used - land-mortgage lending, the main advantage of which is the flexible terms of loans that make them available to small agricultural producers.

In Sweden and Austria the land tax on agricultural land has been abolished, and the tax legislation of the countries provides for tax benefits in the calculation of income tax and provides benefits for investment gains. In the United States of America there is a System of lending to farmers, which is a private cooperative of banks and agricultural associations, whose members are cooperatives of agricultural producers, it accounts for $25 \%$ of loans. Local associations that issue both short-term and long-term loans also operate in the country.

In contrast to Russia, in foreign countries, an indirect form of state support prevails quotas for the import of agricultural products, customs regulation, etc. The indirect form of support allows to solve a wide range of problems of the agricultural industry and even society as a whole, while in our country direct payments are more compensatory, rather than stimulating. A significant difference between foreign and domestic experience is also the practice of interaction of state bodies with commercial structures, which not only allows to expand the opportunities for obtaining financial assistance to agricultural producers, but also helps to attract private capital and public funds for the development of the industry.

Thus, in the EU countries, market instruments and state support instruments are combined - state bodies directly interact with insurance organizations, leasing companies and banks, making their services available to all commodity producers. This system of interaction allows to move away from direct compensatory financing and expands the range of assistance to agricultural producers [9].

The current structure of the Russian agricultural sector hinders the equal access of agricultural producers to state support funds. In this regard, almost half of them are either deprived of access to state support, or receive it in the amount of less than 1 million rubles. At the same time, $1.2 \%$ of large agricultural organizations receive $41 \%$ of the funds allocated by the state to support agriculture [10].

In recent years, State support for cooperatives and small businesses has increased. The federal budget expenditures on the development of the material and technical base of agricultural consumer cooperatives in the period from 2015 to 2019 increased almost 6 -fold from 400 million rubles to 2,341 million rubles, for the support of novice farmers by $3.08 \%$ from 3,200 million rubles to 3,298.5 million rubles, for the development of family farms by 51.54 $\%$ from 3,074.8 million rubles to 4,659.6 million rubles. At the same time, the amount of funding allocated to the development of agricultural cooperation is significantly lower than the state support provided to small businesses (Figure 1).

Thus, in 2019, funding for the development of family farms was almost 2 times more than the grant support for agricultural consumer cooperatives. Moreover, across the country, even a 6-fold increase in funding is not enough to achieve qualitative changes in the development of agricultural cooperation. 


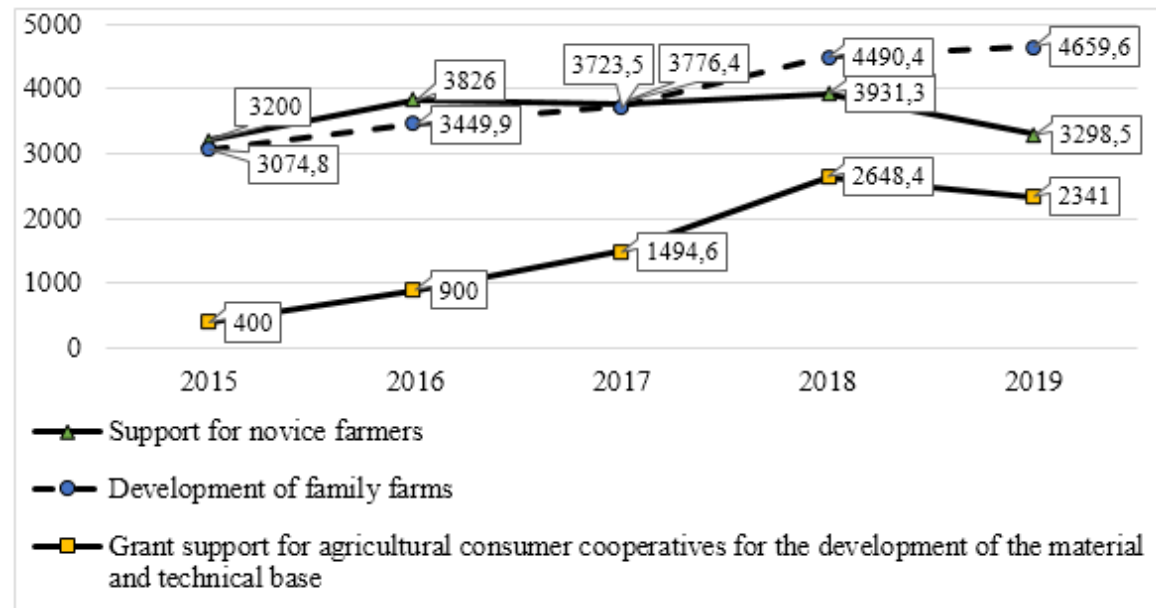

Fig. 1. Dynamics of the volume of state support for small businesses and agricultural cooperation in Russia for 2015-2019, million rubles (The source: developed by the author based on the research materials).

At the same time, the currently established criteria for selecting recipients of financial assistance (grants) do not contribute to improving the efficiency of the functioning of agricultural cooperatives. The mandatory requirement to create new jobs, in their opinion, reduces the attractiveness of grants. A novice farmer must create at least 2 new permanent jobs if the grant amount is 2 million rubles or more, and at least 1 new permanent job if the grant amount is less than 2 million rubles. Cooperatives must create at least 1 new job for every 3 million rubles of the grant, but not less than 1 job per 1 grant.

Even if a farmer sets a minimum wage, an amount equivalent to about 90 per cent of the grant may be spent in five years to pay one worker. According to the authors, it is necessary to set the minimum requirements for creating jobs in a differentiated manner, taking into account the specifics of the activity and the essence of the project for which the grant is involved.

When assessing the effectiveness of the use of grants, an indicator of the increase in the volume of agricultural production compared to the year before the year of receipt of the grant is used. But this does not take into account the reality of achieving indicators. For example, cooperatives for the production of wild berries and fruits have significant potential, but the production volume in them is difficult to predict due to the high dependence on weather conditions [11].

The general concept and mechanisms of state support in our country were inherited from the long-standing practice of protecting agricultural labor from negative external influences used in the pre-reform economy, and focuses on the need to improve the principles and practices of state support in order to strengthen the economy of economic entities and increase the public utility of their activities [12].

A significant problem is the formation of a mutual fund - the solvency of the rural population is much lower than the urban one, but the search for shareholders in the city causes difficulties due to the fact that there are practically no agricultural producers among the urban population. Another major problem is the unsustainable development of rural areas.

Among the problems of cooperation development it is necessary to highlight the lack of a single unifying and coordinating cooperative center. This leads to a lack of complete official information on the state of agricultural cooperation, and difficulties in finding the full amount of statistical information that is relevant at this point in time. The disunity of the cooperative 
participants does not allow lobbying their interests, which is one of the most important incentives for the membership of agricultural producers in cooperatives.

Information, advice and training should be combined in a single center, it is under these conditions that effective interaction will be ensured between those involved in the regulation and support of agricultural cooperation (Ministry of Agriculture of the Russian Federation, Rosagroleasing, Russian Agricultural Bank, etc.). Thus, it is necessary to unite the branches of cooperation represented in rural areas. This will bring agricultural cooperation to a much higher level of competitiveness, which is especially important in the context of the monopoly position of agricultural holdings taking advantage of integration [13].

Khudyakova E. V. and Stratonovich Yu. R. believe that the creation of a single digital communication platform (industry portal) would allow for effective online interaction of all participants in cooperation: peasant farms, large agricultural organizations, households, state and regional authorities, financial institutions, educational institutions.

So, in order to develop agricultural cooperation in the meat subcomplex, using the personal account, the participants of the cooperation will be able to conduct a direct dialogue with each other, form requests for the purchase and sale of livestock, receive the necessary documents, consulting services, attract experts, and also get access to best practices, cases and knowledge bases. Thus, it can be ensured: the creation of a single community of participants in the digital environment, the introduction of common industry standards, transparency of the chain of relations of economic entities, reducing the time and improving the quality of business processes [14].

In the regions of Russia cooperation is developing unevenly. During the period 20182020, 2,133 cooperatives were created, of which: 1,954 agricultural consumer cooperatives and 179 agricultural production cooperatives. At the same time, the leading regions $(10 \mathrm{sub}-$ jects) account for almost half of the cooperatives created in the country - 1,054, in 28 subjects from 1 to 10 cooperatives were created, in 3 subjects (Saint Petersburg, Murmansk Region, Nenets Autonomous District) not a single cooperative was created (Table 1).

Table 1. Number of newly created agricultural cooperatives in leading regions in 2018-2020 (as of 01.11.2020) (The source: developed by the author based on the research materials).

\begin{tabular}{|c|c|c|c|c|}
\hline \multirow[b]{2}{*}{$\begin{array}{l}\text { Federal District } \\
\text { (FD) }\end{array}$} & \multirow[b]{2}{*}{$\begin{array}{c}\text { Federal subjects of } \\
\text { Russia }\end{array}$} & \multicolumn{3}{|c|}{ Number of created cooperatives } \\
\hline & & $\begin{array}{l}\text { Consumer } \\
\text { cooperatives }\end{array}$ & $\begin{array}{l}\text { Production } \\
\text { cooperatives }\end{array}$ & $\begin{array}{c}\text { Total } \\
\text { num- } \\
\text { ber }\end{array}$ \\
\hline Volga FD & $\begin{array}{l}\text { Republic of Bashkorto- } \\
\text { stan }\end{array}$ & 270 & 4 & 274 \\
\hline Volga FD & Republic of Tatarstan & 158 & 1 & 159 \\
\hline Central FD & Belgorod region & 131 & 1 & 132 \\
\hline North Caucasian FD & Republic of Dagestan & 61 & 65 & 126 \\
\hline Southern FD & Krasnodar Region & 87 & 13 & 100 \\
\hline Far Eastern FD & $\begin{array}{l}\text { Republic of Sakha (Ya- } \\
\text { kutia) }\end{array}$ & 54 & 13 & 67 \\
\hline Central FD & Lipetsk region & 55 & 0 & 55 \\
\hline Volga FD & Ulyanovsk region & 47 & 2 & 49 \\
\hline Far Eastern FD & Republic of Buryatia & 46 & 1 & 47 \\
\hline North Caucasian FD & Stavropol Region & 41 & 4 & 45 \\
\hline Total & & 950 & 104 & 1054 \\
\hline
\end{tabular}

The uneven development of cooperation can be explained, first of all, by the existing significant differences in regional policy. In the Federal subjects of Russia the central role is assigned to regional administrations, which determine the attitude to small agribusiness and 
form local programs for the development of peasant farms, households and the cooperative sector.

In our country the level of centralization of management is characterized as high, and in the case when the investment policy does not correspond to the interests of agricultural producers, it gives negative results. An example is the construction of large and super-large wholesale and distribution logistics complexes in the administrative centers of the Federal subjects of Russia in the interests of small and medium-sized businesses, which small businesses did not cooperate with due to obvious logistical inconveniences and economic disadvantages. A positive example of a well-thought-out regional policy, for example, is the construction in the Novgorod region on the initiative of the regional administration in close cooperation with the farmers ' association of high-tech centers of regional scale, close to peasant fields and vegetable gardens. As a result, an impetus was given to increase production volumes, increase the area for growing vegetables and potatoes, and expand the sales channels of the resulting products [15].

Microeconomics factors also have a negative impact on the development of agricultural cooperation. One of them is the need to meet all the requirements imposed by regulatory, law enforcement and supervisory authorities - technical supervision, fire protection, veterinary and sanitary control, etc. At the same time, their volume is not less than in commercial organizations. Compliance with these requirements is mandatory, given the need to protect the health of future consumers of agricultural products collected (produced) by cooperatives.

Profit-oriented commercial organizations employ qualified economists, lawyers, technologists, engineers, and other specialists who receive financial incentives (bonuses). In cooperatives this approach to incentives is not possible due to the fact that the main motivation for members of cooperatives is to satisfy professional ambitions without receiving adequate financial remuneration.

Another factor is the specifics of the products collected (produced) cooperatives. Unlike many products, all agricultural products require special storage conditions. For example, milk is a perishable product that is collected at certain intervals, it is necessary to comply with all the conditions to ensure its safety, while there is no possibility to suspend the process of collecting this product during weekends, sick days and vacations of employees.

Compliance with the conditions of high quality, uniformity, and the required quantity of products is still a problem even for medium-sized agricultural producers. For example, it is necessary to maintain certain qualities of milk collected by the cooperative at the time of delivery to the factory, even from the owners of 1-2 cows. The collected batch must be free of water, traces of antibiotics, bloods impurities, sour milk.

However, unscrupulous members of the cooperative may believe that a small amount of water-diluted or sour milk will not have a negative impact on the quality of the entire batch. In this regard, the milk collectors are forced to take samples from literally every small batch, otherwise the milk of improper quality will not be accepted for processing, and payment for the milk delivered on this day will not be made.

Another negative factor is the limited growth reserves. With the successful operation of the cooperative, entering new markets, the possibility of making new contacts depends on the sources of attracting new members with the products they produce. This follows from the fact that the possibility of fulfilling the commitments of the members of the cooperative in the first place, by households, physically and virtually restricted to the «power of the asset» (the area of cultivated land, the presence of agricultural machinery, animal performance, etc.), that means the limited growth of the efficiency of their work.

The determinant factors that hinder the development of the cooperative movement in the agricultural sector can be grouped into 3 groups:

1. Factors related to human capital (Figure 2). 
Problems related to human capital

The loss of cultural traditions of conducting cooperative activities based on the principles of solidarity, trust and democracy.

Negative perception of the prospects of agricultural cooperation.

The decline and aging of the rural population, as well as the population directly involved in agricultural production.

Poor awareness of the rural population about the cooperative movement, about the advantages of cooperative activities.

Lack of experience of involvement in cooperative activities, difficulties in selecting professional managers.

The dominance of individual interests over group interests, the desire to extract personal benefits to the detriment of the interests of other participants in cooperative activities, taking into account the interests of the owners of control participation and ignoring the interests of small owners and employees.

Fig. 2. Factors of cooperation development in the agricultural sector - problems related to human capital (Source: developed by the author based on the research materials).

2. Factors related to financial, land, and logistical resources (Figure 3).

Problems related to financial, land, material and technical resources

Difficulties with the formation of a mutual fund due to the lower solvency of the rural population compared to the urban population.

Unsettled land relations, the divergence of the circle of persons who own agricultural land, and the circle of persons directly engaged in agricultural production.

The weakness of the material base necessary for cooperation.

Existing difficulties in acquiring the necessary material resources and agricultural machinery.

Limited access to state support funds and financial and credit resources.

Illegal receipt of financial assistance, violation of the terms of subsidies, implementation of fraudulent actions.

Limited growth reserves - depending on the area of cultivated land, the productivity of farm animals, the availability of modern technical means.

Fig. 3. Factors of cooperation development in the agricultural sector - problems related to financial, land, material and technical resources (Source: developed by the author based on the research materials).

3. Factors related to state regulation and interaction with regional authorities (Figure 4). 
Problems related to state regulation and interaction with regional authorities

Imperfect legislation in the field of cooperation, including the legally established division of cooperatives, which creates restrictions and requires compliance with a large number of formal procedures.

Insufficient level of state support, tax incentives and indirect support measures.

The existing criteria for selecting recipients of financial assistance reduce the interest in receiving it.

The insufficient level of interaction of the state with commercial structures, including insurance organizations, leasing companies, which does not allow to increase the access of cooperatives to their services and expand the range of assistance provided.

Providing state assistance not only to cooperatives, but also to their competitors wholesale and logistics centers and large storage bases.

Significant differences in regional policy, inconsistency of investment policy with the interests of local agricultural producers.

Low level of protection of property rights and overall political, legal and administrative support for cooperation.

Fig. 4. Factors of state regulation and interaction with regional authorities (Source: developed by the author on the basis of research materials).

Cooperation is one of the most effective mechanisms for adapting the agricultural sector to the conditions of the new economic reality. However, in our country, the general state of cooperation can be described as unstable.

\section{Conclusion}

Within the framework of the conducted scientific research, the measures used in the United States of America and the countries of the European Union for the spread of cooperation are considered, the determinant factors hindering the development of agricultural cooperation in Russia are identified, their author's grouping is proposed: factors related to human capital; the use of financial, land and material resources; with state regulation and interaction with regional authorities.

In solving these problems a significant role is assigned to state regulation, including in terms of increasing the volume of financial support, improving regulatory regulation, using indirect forms of state support and creating the conditions necessary for the effective functioning of agricultural cooperatives, especially since the development of the cooperative sector has reached a new level and is among the priority areas of state policy.

\section{References}

1. A.V. Tkach, G.N. Dudukalova, A.S. Nechitaylov, Complex Systems: Innovation and Sustainability in the Digital Age, 1, 437-447 (2020)

2. L .Matraeva, O. Kaurova, E. Vasiutina, S. Erokhin, European Research Studies Journal, 21(3), 206-217 (2018)

3. A.N. Maloletko, G.I. Andryushchenko, O.V. Kaurova, E.A. Mityushina, A.A. Shatskii, ESPACIOS, 38 (49), 19-21 (2017)

4. V.M. Kapitsyn, O.A. Gerasimenko, L.N.Andronova, Studies on Russian Economic Development, 1, 67-74 (2017) doi.org/10.1134/S107570071701004X 
5. A.P. Zinchenko, Studies on Russian Economic Development, 2, 140-146 (2017) doi.org/ 10.1134/S1075700717020137

6. D.V. Dianov, A.E. Suglobov, E.I .Kuznetsova, A.V. Rusavskaya, A.V. Minakov. International Journal of Engineering and Technology (UAE), 7 (3.15), 230-232 (2018)

7. A. Suglobov, V. Bessonov. IOP Conference Series: Earth and Environmental Science electronic resource, 012080 (2019)

8. V. Uzun, N. Shagaida, Z. Lerman, Land Use Policy, 83, 475-487 (2019) doi: /10.1016/j.landusepol.2019.02.018

9. L.N Usenko, Y.G Chernysheva, V.A Guzey, O.M. Todorova, A.M. Usenko, International journal of trade and global markets, 2-3, 160-167 (2017) doi: 10.1504/ijtgm.2017.086074

10. M. Slozhenkina, I. Gorlov, M. Kholodova, O. Kholodov, O. Shakhbazova, D. Mosolova, AGRITECH-III-2020 IOP Publishing IOP Conf. Series: Earth and Environmental Science, 548 (2020) doi:10.1088/1755-1315/548/8/082037

11. O. Isaeva, M. Kabanenko, A. Chistyakov, L. Dubrova, N. Filin, E3s Web of Conferences 175, 13004 (2020) doi: 10.1051/e3sconf/202017513022

12. V.I. Denisov, Studies on Russian Economic Development, 1, 66-73 (2019) doi.org/10.1134/S1075700719010040

13. R. F. Gataullin, A. A. Askarov, G. N. Khuzhakhmetova, N. V. Yarkov, Economic Region, 2, 271-284 (2015) doi 10.17059/2015-2-22

14. I. Boldyreva, O. Andryushchenko, A. Nikitaeva, Z. Udalova, J. Rudash, Journal of environmental management and tourism, 8, 4 (20), 642-647 (2017) doi:10.14505/ jemt.v8.3(19). 15

15. N. D. Avarsky, A.V. Altapov, and T. M. Kuznetsova, Economics of agricultural and processing enterprises, 1, 22-31 (2017)

16. I. Boldyreva, O. Andryushchenko, A. Nikitaeva, Z. Udalova, J. Rudash, Journal of environmental management and tourism, 4 (20), 642-647 (2017) doi:10.14505/ jemt.v8.3(19). 15 